THE LANCET, MarCh 25, 1876.

\section{Climical Aectures}

\section{LISTER'S TRFATMENT OF WOUNDS AND ABSCESSES BY THE ANTISEPTIC METHOD.}

BY THOMAS SMITH, F.R.C.S., SUBGBOT YO ST. BARTHOLOYRW'S HOBPITAL.

\section{LECTURE I.}

Gentlemen,-As many of you are aware, I am endeavouring at the present time, with Mr. Vernon's assistance, to carry out Mr. Lister's method of treating wounds antiseptically, and as some of you may be interested in the result, I propose in this lecture to explain, as briefly as I can, the theory upon which Lister's antiseptic treatment is based, the facts from which that theory is adduced, and the advantages Mr. Lister claims for the plan.

I shall not at present give the results of my experience, nor shall I now express any opinion as to the merits or demerits of this treatment. I would rather wait until a fuller experience justifies $m e$ in speaking with some authority.

In taking up a subject of this kind it is rery difficult to avoid a spirit of partisanship, since on the one side there are surgeons whose opinion is entitled to respect who are opposed to the system, either on d priori grounds or in consequence of an unfavourable experience of its results; and on the other side are ranged those who have come to an opposite conclusion, and mostly after having put the plan to a practical test.

Under existing circumstances I should advise you to form your own independent opinions from your own observation of results. I intend to do so, and I propose to give the plan at least one year's trial, employing the treatment especially in what may be called test cases; I mean in cases where the antiseptic method is fairly put on its trial, and where an opportunity occurs for such advantages as it is said to possess to become plainly apparent.

There are two preliminary conditions which Mr. Lister has a right to demand of those who profess to make trial of his system : first, that they should at least provisionally accept his theory; secondly, that they should know what his practice is, and should carry it out even to the minutest particular. They must provisionally accept the theory, or the details of the practice will in some respects appear so frivolous that they are sure to be occasionally neglected; while if the soundness of the theory be accepted, it will be seen that the observance of these details is thoroughly reasonable. Mr. Lister has a right to insist that those who profess to give his practice a fair trial should observe its minutest details, since no one can be truly said to carry out Lister's plan who stops short in the execution of details prescribed by the author as necessary to success.

Now, in order to fulfil the first condition, I have, for the present at least, agreed to accept Mr. Lister's theory (what it is I will tell you directly). And lest I should fail in the second through a want of knowledge, I visited Edinburgh myself last summer, and had the advantage of personal instruction from $\mathrm{Mr}$. Lister himself; and subsequently my house-surgeon, Mr. Vernon, was good enough to stay there for a time, when both Mr. Lister and Mr. Annandale gave him every opportunity of learning the practice of antiseptic surgery. These gentlemen not only succeeded in teaching Mr. Vernon the details of their treatment, but happily fired him with the enthusiasm necessary to carry them out with a good will on his return to London. Whatever may be the result of antiseptic surgery in my wards, I shall remain very much indebted to Mr. Lister, Mr. Annandale, and Mr. Ternon.

The theory, or, one may now say, the facts on which Mr Lister's antigeptic treatment rests are as follows :-

1st. That in the dust of the atmosphere, and on matter No. 2743 with which it is in contact, there are the germs of minute organisms which, under favourable circumstances, induce putrefaction in fluids and solids capable of that change, in the same manner as the yeast-plant occasions the alcoholie fermentation in a saccharine solution.

2nd. That putrefaction is not occasioned by the chemical action of oxygen or any other gas, but by the fermentative agency of these organisms.

3rd. That the vitality or potency of the germs can be destroyed by heat, and by various chemical substances, which we call, in surgery, "antiseptics."

Now, I am not going to ask you to believe these statements on my authority, but I will shortly refer to the results of experiments performed by Pasteur, Lister, Sanderson, Tyndall, and others, which justify the above conclusions.

It is scarcely necessary to state that organic fluids, like milk, urine, and blood, infusion of meat, \&c., if kept in contact with the air at ordinary temperatures, will ere long decompose or putrefy, and will give evidence of putrefaction by turbidity (if the fluid be originally clear), by the evolution of offensive gases, and by the development within them of bacteria.

Again, I need do no more than remind you that prolonged boiling will not of itself preserve such fluids from putrefaction. Yet any of these or similar fluids may be kept free from putrefaction for an indefinite time, in spite of free access of the atmospheric gases, provided that the fluid has been boiled at the outset to destroy any organisms in it, and that the vessel containing it has been thoroughly purified by heat, and that the dust of the air is excluded. The exclusion of the dust may be effected in various ways. In some of Pasteur's first experiments it was done by having the neck of the flask which contained the liquid drawn ont by aid of heat into a fine tube bent at various angles, in which form, though open at the end, and allowing perpetual entrance and exit of air, it arrested all particles suspended in it, and the urine or other fluid which was the subject of experiment remained permanently unaltered. Or, again, the same object may be attained by having the mouth of the flask plugged with a mass of purified cotton-wool, which effectually filters of its dust the air that enters the vessel in consequence of the condensation which alternates with expansion in the diurnal changes of temperature. But if the neck of the flask is broken short in Pasteur's experiment, or the plug of cotton-wool removed, organisms are sure to show themselves before many days have passed. Even more striking is the method adopted by Mr. Lister, who decants the boiled organic liquids into wine-glasses purified by heat, and each covered with a glass cap similarly purified and a glass shade, scrupulous care being taken to avoid the entrance of dust during the process of decanting. Neither cap nor shade fits closely, so that a constant interchange takes place between the external air and that in the wine-glass, yet the double protection afforded by the cap and shade effectually excludes dust, and the result is, that although the organic liquids gradually diminish in bulk by evaporation, and in the course of months dry up altogether, no organisms make their appearance from first to last, nor does putrefaction or any other fermentative change occur. If, however, the glass shade and cap are removed for a few minutes and replaced, fungi or bacteria soon show themselves. But he has found that if the glass cap be only lifted for a second or two in an ordinary apartment free from draughts there is practically no risk of the entrance of any organism in the short period of exposure.

Further, it has been shown by Pasteur and other observers that it is by no means essential to the success of such experiments that the organic liquids should be boiled, but that when circumstances admit of their being withdrawn uncontaminated from their natural receptacles, such as the urinary bladder, the bloodvessels, the udder of the cow, or the shell of a fresh-laid egg, they will remain free from organisms and from putrefaction when kept in pure vessels and protected from dust.

It has also been discovered that impure air will purify itself by mere subsidence of its dust. Pasteur long ago proved that putrescible fluids could be kept free from putrefaction in air taken from cellars free from draughts, when the solid particles of the atmosphere had had time to deposit themselves by subsidence; and Prof. Tyudall has recently subjected air purified by being kept at rest to very 
searching tests to ascertain if it will excite putrefaction in putrescible solutions. He has found that solutions of meat, cheese, turnip, \&c., first subjected to a high temperature, can be kept free from putrefaction for an indefinite time exposed to the air-closed boxes that have been kept at rest a day or two, to allow the dust to subside, precautions being taken to prevent the said dust rising again by coating the inside of the box with glycerine. The same experimenter bas demonstrated the fact that the air which has been thus rendered incapable of exciting putrefactioni.e., aseptic-is also optically pure: that is, that there are no particles or motes to be detected in it when illuminated by a beam of electric light in a darkened room.

I think, then, we are justified in concluding that in the dust of the atmosphere there are, such things as fermentative particles, organisms, germs, or whatever you like to call them, and that these, under favourable circumstances, induce putrefaction in fluids and solids capable of the process; that without these germs putrefaction and the formation of bacteria does not take place, and, finally, that these germs can be destroyed or removed from the atmosphere by the various means that I have above described.

Let me bere remark, as having an important bearing upon Mr. Lister's practice, that in the case of those fluids that have been kept free from putrefaction by any of the above described means, the addition of the smallest drop of ordinary water, or the contact of a glass rod that has not been specially treated to render it aseptic, will almost certainly excite putrefaction, though all other prescribed conditions are scrupulously carried out to prevent its occurrence.

On the other hand, Mr. Lister has found that when any partion of apparatus used in investigations on this subject oannot conveniently be purified by heat, the object may be attained by washing the glass or other material with a strong watery solution of carbolic acid, and drying it with a carbolised rag, and in the course of a long series of experiments he has invariably found this antiseptic agent as efficacious as the flame of a spirit-lamp in preventing the growth of organisms and the occurrence of putrefaction.

Mr. Lister's object in the treatment of wounds and abscesses is to exclude from them these germs or organisms that float in the atmosphere and are the causes of putrefaction, and the means he employs for effecting this purpose he recommends, not as the best that can be used, but as the best that he has been able up to the present bime to devise; and although Mr. Lister considers the truth of his theory incontrovertible, yet he does not claim to have brought his practice to perfection.

Mr. Lister claims for his plan that when it can be carried out with due care and proper observance of details, he can, as a rule, secure that an open wound should heal after the manner of a subcutaneous injury - that is, without inflammation or constitutional fever, and for the most part without suppuration; while, if suppuration occurs, he secures that it shall not be putrefactive - that is, accompanied by the changes that we consider evidences of putrefaction, such as the formation of bacteria and the evolution of fetid gases.*

In the treatment of abscesses by the antiseptic method, Mr. Lister believes that he has effected an entire revolution in the course of the disease after the cavity bas been opened, and to this I will more particularly allude in my next lecture. But I may here mention that, along with many local advantages, the patient is said to be free from all danger of irritative fever as the immediate consequence, and from hectic at a later stage.

I said that these adrantages are claimed for the antiseptic method when it can be carried out with due care and a proper ohservance of details - that is to say, in cases where the surgeon himself inflicts the wound on an unbroken skin; for in this case he can protect the part against the entrance of putrefactive ferments, whereas when sinuses have formed, or when a wound has been some time exposed to the air, abundant sources of putrefaction already exist in the wound or abscess ; nor is there at present any means by which, under there conditions, they can with certainty be all destroyed. You can thus understand how it is that Mr. Lister considers himself sure of success where

* The local adrantages, if secured in individual cases, must of conrse affect the general alubrity of a hospital. On this subject see The Effect of the Antiseptic Treatment on the General Salubrity of Sargical Hospitals by J. Lister, F.R.S., Brit. Med, Jour., 1875, vol, ii, p. 769 . he applies his treatment to an abscess which he himself opens, or to a wound he has made, and that he would generally expect success when dealing with a recent compound fracture or wound into a joint; whereas be would scarcely be disappointed at a failure if he applied his treatment to a case where sinuses already existed, or where an open wound had long been exposed to the air.

I must state these things explicitly to you in justice to Mr. Lister, that you may judge fairly of the results of the antiseptic treatment, understanding what it cannot do, as well as knowing the advantages claimed for it by its author. It is also only just to Mr. Lister, and essential, in order to enable you to form a fair estimate of the results of his method, to remember that he is far from regarding putrefaction as the only canse of suppuration. On the contrary, he has long since pointed out that any antiseptic substance, such as carbolic acid, if applied continuously to the exposed tissues of a wound, stimulates them to granulation, and the granulations to the formation of pus, giving rise to what he has termed "antiseptic suppuration," due to the direct chemical stimulus of the antiseptic. He has also expressed the belief that putrefaction acts in a precisely similar manner in causing suppuration, the products of putrefaction being acrid chemical substances; but that there is this all-important difference between the two cases-that the antiseptic acts only on the part to which it is applied, whereas putrefaction, being a fermentation, extends itself into all the recesses of a wound or abscess, where blood or sloughs, pus or serum, affords a nidus for the development of the bacteria. Further, Mr. Lister has directed attention to the important truth that suppuration, besides being brought about in this manner by the direct stimulus of chemical irritants, may be produced by ordinary inflammation without the access of any external disturbance, putrefactive or otherwise, as in the familiar case of an ordinary deep-seated abscess, the contents of which when evacuated are free from putrefaction. This ordinary inflammation he believes to be due to excited nervous action, and the commonest of all causes of it in surgical practice is tension, occasioned by blood or serum being pent up within the cavity of a wound; and he has insisted upon the fact that, in consequence of the irritating influence of the antiseptic material in the spray and sponges, the sanguineo-serous discharge is greater in the earlier periods from a wound treated antiseptically than from one managed in the ordinary way. Hence it is doubly necessary to provide free escape for this serous effusion, which is done by means of drainage-tubes; and if these be neglected or inadequate, tension will inevitably result, with corresponding inflammation, and in due time suppuration. Lastly, we must bear in mind that in flammation caused in this manner by tension, like any other ordinary inflammation, will be attended in proportion to its intensity by constitutional disturbance or fever.

If, therefore, we see suppuration make its appearance, or inflammatory disturbance and febrile excitement, in any case treated antiseptically, we need not necessarily infer that the antisentic method is at fault until we have seen if we can discover some cause, other than putrefactive, which may account for the phenomena.

It will be obvious to those of you who have followed me thus far, that though all that $I$ have stated may be absolately true in theory, and though Mr. Lister's practice may be thoroughly sound in a chemical sense, yet pathologically it may be unsound. I mean that the antiseptic treatment may succeed in preventing the occurrence of putrefaction and the development of bacteria in wounds and open abscesses, yet this freedom from putrefaction does not necessarily imply an absence of local inflammation and constitutional irritation. Now this is what I want you especially to observe for yourselves: first, if the secretions of wounds and abscesses treated antiseptically are free from putrefaction; and secondly, if, together with this absence of decomposition, you have an absence of local inflammation and constitutional fever-other sources of these conditions being excluded.

That you may judge of these things the better and more certainly, I use the antiseptic method to those cases which, under ordinary treatment, are specially liable to local manifestations of inflammation, and are generally the sources of well-marked constitutional disturbance. I have not used the plan in ordinary amputations, removals of the breast, tumours, operations for hernia, nor in the treatment 
of acute superficial abscesses, for in these the result of surgery in a healthy hospital is usually satisfactory; but in resections of large joints, in wounds of joints and compound fractures, in deep abscesses, and especially in chronic abscesses connected with joint disease or caries of bone.

In judging of the results of the antiseptic treatment in our hands, I must beg you to bear in mind the facts which were published by Prof. Tyndall in January last. I must ask you to observe that even in the chemical laboratory there are difficulties to be overcome and minute details to be observed in order to obtain uniform results; and that, even in the hands of masters of the art, notwithstanding all care, sources of error will sometimes occur, and a fallacious result be obtained. Now, if this be the case under the circumstances I have referred to, how much more difficult must it be to carry out the necessary details when beginners like ourselves are dealing with the living tissues of the human body.

\section{NOTES ON ASYLUMS FOR THE INSANE IN AMERICA.}

BY JOHN CHARLES BUCKNILL, M.D., F.R.S. (Continued from p. 419.)

But I must not further delay to endeavour to make it apparent whereabouts the Americans are in their opinions and practice.

The discussion at Nashville was mooted upon an able paper by Dr. Ramsey, and it was concluded by the President declaring that the members of the Association were "essentially a unit upon the question as presented by Dr. Ramsey." This, however, was not quite correct, for an Abdiel was found in Dr. Lett, of Canada, who boldly declared, "So far as $\mathrm{my}$ experience goes, I think this is simply a question between good attendants and restraint." Dr. Worthington also came very near to rebellion against the law of the majority when he asserted that in his asylum, the Friends' Asylum at Philadelphia, "since the use of mechanical restraints has been almost entirely discontinued there has been far less trouble in the management of the patients." The unanimous opinion of the remaining members of the Association seems to be expressed in the following words of Dr. Smith, superintendent of the State Asylum, Mo. "This question has been very freely discussed at previous meetings of this Association, and the result was almost entire uniformity of sentiment in all well-conducted American institutions for the insane. No restraint is the general rule, and restraint the exception; while for many years past the tendency in this country has evidently been to reach the point of least possible restraint, there have been very few if any converts to the non-restraint system in the true sense of the term."

This being the position taken, I shall endeavour to show by their own declarations what the superintendents of the State asglums consider the least possible amount of restraint and the description of eases in which they think themselves justified in employing it.

Dr. Orpheus Evarts, of the Indiana Hospital for the Insane, said: "I think we are all agreed; but the question seems to be how much and what kind of restraint is required? I know of no other object in sending these persons to an insane hospital than that of proper restraint...... When I assumed charge of the Indiana Hospital I found perhaps fifteen per cent. of the patients wearing some kind of mechanical restraint. I have reduced the ratio to not far from two per cent. Below that I find it impracticable to go." $-D r$. Green, of the Georgia State Asylum, said: "I do not think that all the restraints we employ amount to two per cent. per annum with our 560 patients. I certainly concur in the positive and absolute necessity of personal restraint." Dr. Green said that he applies mechanical restraint to four different classes of patients-namely, (1) to suicidal patients, (2) to "persons who will not remain in bed," (3) "to persons who persiscently denude themselves of all clothing," and lastly (4) " to the inveterate masturbator."-Dr. Ramsey, after mentioning that Dr. Bell had reduced restraints in the M.Lean Asylum to less than one per cent. so long ago as 1839, said: " Have we not sometimes fallen below it on a plea of economy, or through a willingness to shirk the unceasing, patient, and thoughtful attention a large number of patients in hospital need, and thus brought upon ourselves and the institutions under our care the odium and the pernicious legislation that seem to have sprung out of, or at least to have closely followed, some sharp criticiems in recent publications, and the acrimonious utterances of intense humanitarians, or persons whose mental integrity is at least questionable? And to just such results shall we be ever in danger so long as restraint may be deemed necessary, unless with unceasing vigilance we guard against the abuses which with its use are exceedingly liable to creep in." A very remarkable passage this, as reasonable as it is forcible and eloquent. Dr. Ramsey thinks that mechanical restraint is "a valuable, if not indispensable, auxiliary in the treatment"-(1) of " cases of acute mania characterised by violent destructive and mischievous propensities"; (2) in patients "who wound themselves, creating ulcers that would never heal themselves, unless their hands were confined"; (3) " it is the only safe course in guarding against the dangerous violence to which the epileptic insane are often liable"; (4) "persons whose feelings are greatly pervertedexceedingly irascible-prone to see insults, or evidence of conspiracy - are sometimes little less ferocious than wild beasts, and feel little or no regard for human life......for them seclusion or restraint, for varying periods, seems to be necessary, and, for a small portion of this class, almost continuous"; (5) "how shall we treat that so frequently fatal disease, acute delirious mania, if we do not apply restraint to secure recumbency?" It will be observed that none of the five classes enumerated by Dr. Ramsey as requiring restraint tally with those of Dr. Evarts, so that already we have nine classes of lunatics who need mechanical restraint in America. Dr. Slusser, of the Ohio Hospital for the Insane, adds to the number. "I have met with a class requiring restraint not alluded to by the writer, Dr. Ramsey. I refer to those who persistently walk or stand until their extremities become swollen, and they give evident signs of physical prostration. I have no way of controlling such but by tying them down on a seat. If there is any less objectionable mode, I should like to know it. Then we have a class of noisy patients, harmless in every other respect, but so loquacious and boisterous that they disturb the whole ward." With this climax we might well conclude this astounding classification, did not other superintendents in their remarks afford us the means of adding to it: for instance, patients needing forced alimentation (Dr. Curwen), patients who butt their heads against the wall (Dr. Forbes and Dr. Kilbourne), and delusional cases, who are very quiet, then suddenly rise up and make a violent attack upon somebody (Dr. Carriel) - fourteen classes of the insane altogether who absolutely need mechanical restraint in the State asylums of America, according to the opinions and practice of their medical superintendents. It would be interesting to know how many classes of the insane our American brethren can reckon who do not require this indispensable means of treatment.

It would be tedious and uselesa to discuss the need in all these classes with the intention of showing by what means in England patients included in them would be treated without the use of strait-waistcoats, muffs, camisoles, or locked chairs: are they not written in the pages of THr LANCET in the days of the last generation? I shall, however, as an example, take the remarks made upon one class -namely, those patients who denude themselves or destroy their clothing-to indicate the lack of resource, which is one cause of all this employment of restraint. We know, by long and large experience, how easy it is to allow a lunatic perfect freedom of all muscular movement and yet to prevent him from stripping bimself, or from destroying his clothing, by the employment of outer clothes so fashioned that he cannot remove them, and so strong that he cannot easily destroy them. This, with some care on the part of the attendants, is a perfect and facile remedy. Yet Dr. Curwen says: "When patients are obstinately bent on destroying their own clothing or that of others, it is safest and best to ennfine their hands." Dr. Eastman says : "At the Worcester Hospital there are a large number of chronic cases, who are 